\title{
A Smartphone-Based Information Communication Technology Solution for Primary Modifiable Risk Factors for Noncommunicable Diseases: Pilot and Feasibility Study in Norway
}

Inger Torhild Gram ${ }^{1,2}, \mathrm{MD}, \mathrm{PhD}$; Guri Skeie ${ }^{2}, \mathrm{PhD}$; Sunday Oluwafemi Oyeyemi ${ }^{2}, \mathrm{MD}, \mathrm{PhD}$; Kristin Benjaminsen Borch $^{2}, \mathrm{PhD}$; Laila Arnesdatter Hopstock ${ }^{2}$, PhD; Maja-Lisa Løchen², MD, PhD

${ }^{1}$ Norwegian Centre for E-health Research, University Hospital of North Norway, Troms $\varnothing$, Norway
${ }^{2}$ Department of Community Medicine, Faculty of Health Sciences, UiT The Arctic University of Norway, Troms $\varnothing$, Norway

\section{Corresponding Author:}

Inger Torhild Gram, MD, $\mathrm{PhD}$

Norwegian Centre for E-health Research

University Hospital of North Norway

Forskningsparken i Breivika, 3rd floor

Sykehusvn. 23

Tromsø, 9019

Norway

Phone: 4792401177

Email: inger.gram@ehealthresearch.no

\section{Abstract}

Background: Cardiovascular diseases, cancers, chronic respiratory diseases, and diabetes are the 4 main noncommunicable diseases. These noncommunicable diseases share 4 modifiable risk factors (tobacco use, harmful use of alcohol, physical inactivity, and unhealthy diet). Short smartphone surveys have the potential to identify modifiable risk factors for individuals to monitor trends.

Objective: We aimed to pilot a smartphone-based information communication technology solution to collect nationally representative data, annually, on 4 modifiable risk factors.

Methods: We developed an information communication technology solution with functionalities for capturing sensitive data from smartphones, receiving, and handling data in accordance with general data protection regulations. The main survey comprised 26 questions: 8 on socioeconomic factors, 17 on the 4 risk factors, and 1 about current or previous noncommunicable diseases. For answers to the continuous questions, a keyboard was displayed for entering numbers; there were preset upper and lower limits for acceptable response values. For categorical questions, pull-down menus with response options were displayed. The second survey comprised 9 yes-or-no questions. For both surveys, we used SMS text messaging. For the main survey, we invited 11,000 individuals, aged 16 to 69 years, selected randomly from the Norwegian National Population Registry (1000 from each of the 11 counties). For the second survey, we invited a random sample of 100 individuals from each county who had not responded to the main survey. All data, except county of residence, were self-reported. We calculated the distribution for socioeconomic background, tobacco use, diet, physical activity, and health condition factors overall and by sex.

Results: The response rate was 21.9\% (2303/11,000; women: 1397/2263; 61.7\%, men: 866/2263, 38.3\%; missing: 40/2303, $1.7 \%$ ). The median age for men was 52 years (IQR 40-61); the median age for women was 48 years (IQR 35-58). The main reported reason for nonparticipation in the main survey was that the sender of the initial SMS was unknown.

Conclusions: We successfully developed and piloted a smartphone-based information communication technology solution for collecting data on the 4 modifiable risk factors for the 4 main noncommunicable diseases. Approximately 1 in 5 invitees responded; thus, these data may not be nationally representative. The smartphone-based information communication technology solution should be further developed with the long-term goal to reduce premature mortality from the 4 main noncommunicable diseases.

(JMIR Form Res 2022;6(2):e33636) doi: 10.2196/33636 


\section{KEYWORDS}

eHealth; feasibility study; modifiable risk factor; noncommunicable disease; pilot study; smartphone-based information communication technology solution; short text message service; feasibility; risk; factor; information communication technology; smartphone; development; monitoring

\section{Introduction}

Cardiovascular diseases, cancers, chronic respiratory diseases, and diabetes are commonly grouped as the main noncommunicable diseases as they are the world's biggest killers [1-3]. These noncommunicable diseases share 4 modifiable risk factors (tobacco use, harmful use of alcohol, physical inactivity, and unhealthy diet). An important part of the United Nation's Sustainable Development Goal target 3.4 is to reduce premature mortality from the 4 main noncommunicable diseases by one-third relative to 2015 levels, by 2030 [4]. Encouraging reduced tobacco use, less harmful use of alcohol, increased physical activity, and healthy diet are simple and cost-effective measures to reduce premature death and disability from the 4 main noncommunicable diseases [5]. Surveillance of the 4 modifiable risk factors is crucial to be able to prevent and control premature death from the 4 main noncommunicable diseases according to the 2030 Sustainable Development Goal agenda [3].

In 2013, the World Health Assembly, the decision-making body of the World Health Organization, adopted a Global Monitoring Framework for noncommunicable diseases with 25 key indicators to track progress in prevention and control of noncommunicable diseases [6]. Before this, the World Health Organization had already introduced the STEPwise approach [7] for the surveillance of noncommunicable disease risk factors. Step 1 included self-reported demographic and behavioral risk factors as well as history of noncommunicable diseases and related conditions; step 2 included physical measurements; step 3 consisted of biochemical measurements.

Statistics Norway performs annual surveys, with representative samples, on tobacco use [8]. Furthermore, there have been several large population surveys [9-12] conducted in various regions and counties during the last fifty years, repeated at approximately 8-year intervals, which have collected some of the data included in the 3 steps of the STEPwise approach $[11,12]$. In addition, special surveys have been conducted, usually with 10-year intervals, to collect data on detailed dietary intake [9]. Special surveys on physical and sedentary activity have also been conducted with more than 5-year intervals [10]. In summary, there has been a lack of annual data on tobacco use, the harmful use of alcohol, physical inactivity, and unhealthy diet from a nationally representative sample. The Norwegian legislation on public health work [13] requires counties and municipalities to have an overview regarding risk factors, health conditions, and measures to promote health in their respective populations.

In Norway, more than $95 \%$ of individuals aged 16 to 54 years, and between $74 \%$ to $88 \%$ of those aged 55 to 74 years, have smartphones [14]. Short smartphone surveys have the potential to identify modifiable risk factors for individuals and monitor trends. Our main objective was to develop a smartphone-based information communication technology solution with functionalities for collecting data annually on the 4 modifiable risk factors. The secondary objective was to collect nationally representative data.

\section{Methods}

\section{Study Design}

This pilot study, which included a smartphone-based solution, a website, and 2 smartphone surveys, was developed over a 2-year period and conducted during fall 2019.

\section{Development of the Smartphone-Based Information Communication Technology Solution}

The details of the technical and architectural parts of the solution were developed by a private enterprise (Healthcom). For answers to the continuous questions, a keyboard was displayed for entering numbers (Figure 1); there were preset upper and lower limits for acceptable response values (Figure 2). For categorical questions, pull-down menus with response options were displayed (Figure 3).

The information communication technology solution was intended for capturing sensitive data from smartphones and was developed in accordance with general data protection regulations [15]. The cloud-based information communication technology solution automatically created a unique identification number for each respondent, when the initial SMS dialogue started. If the respondent clicked on the survey link later, the respondent's unique identifier was detected, and the participant could continue to fill in the answers. When the survey was submitted, the responses were anonymized. Subsequently, for analyses and storage, data were transferred to the Research Electronic Data Capture database hosted by the University Hospital of North Norway (Northern Norway Regional Health Authority server system) [16,17]. Communication with the database (over the internet and hospital intranet) was encrypted, and 2-factor authentication was required for researchers retrieving the data. 
Figure 1. Screenshot of data entry keyboard.

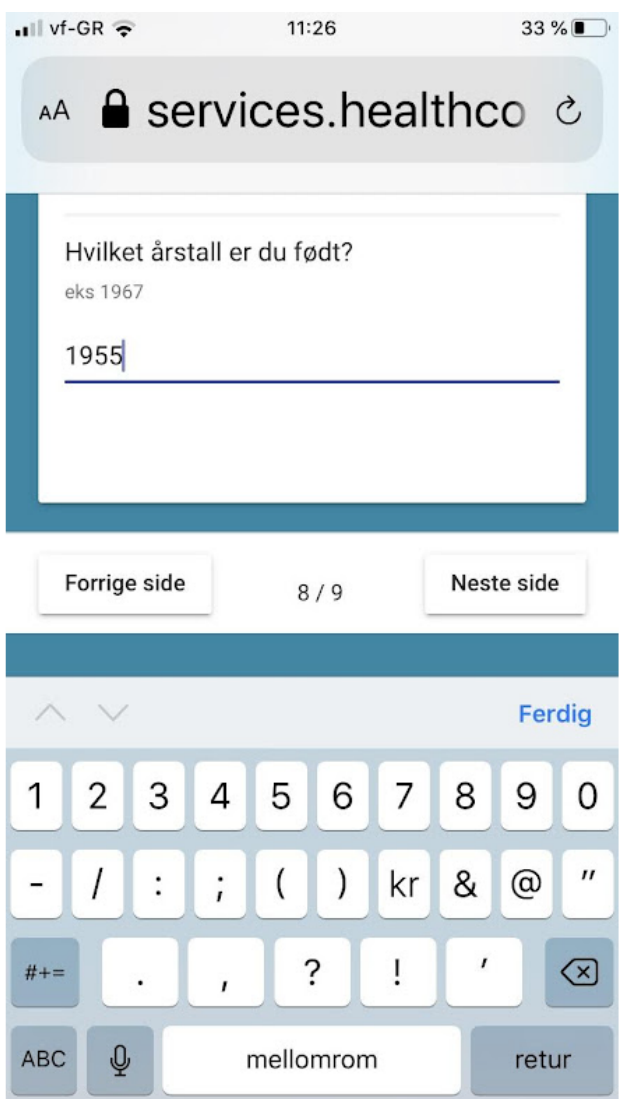

Figure 2. Screenshot of smartphone-based survey.

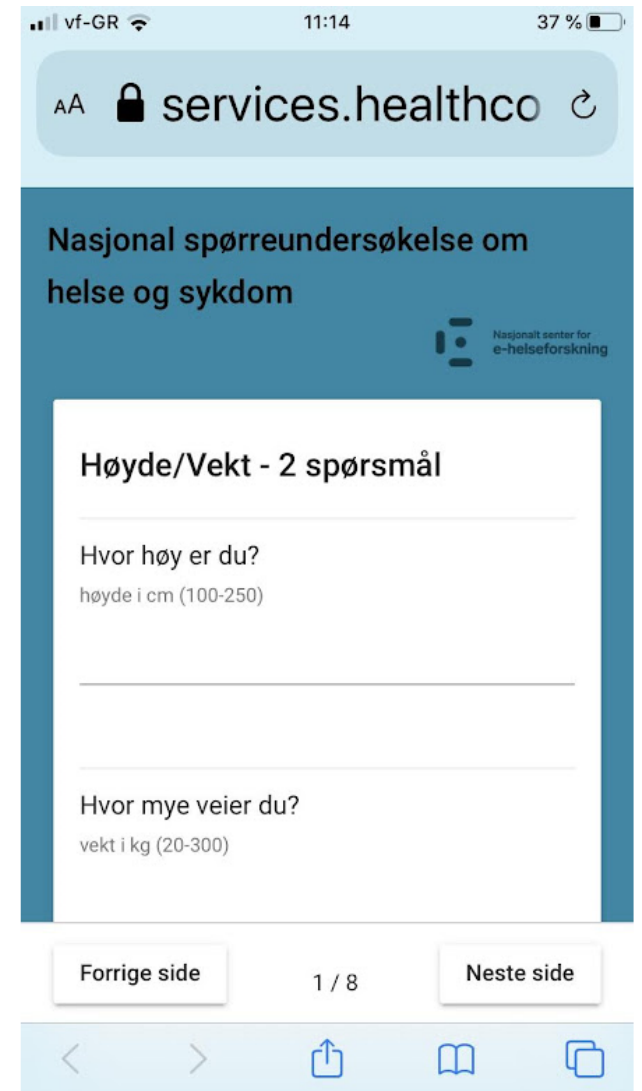


Figure 3. Screenshot of pull-down menus.

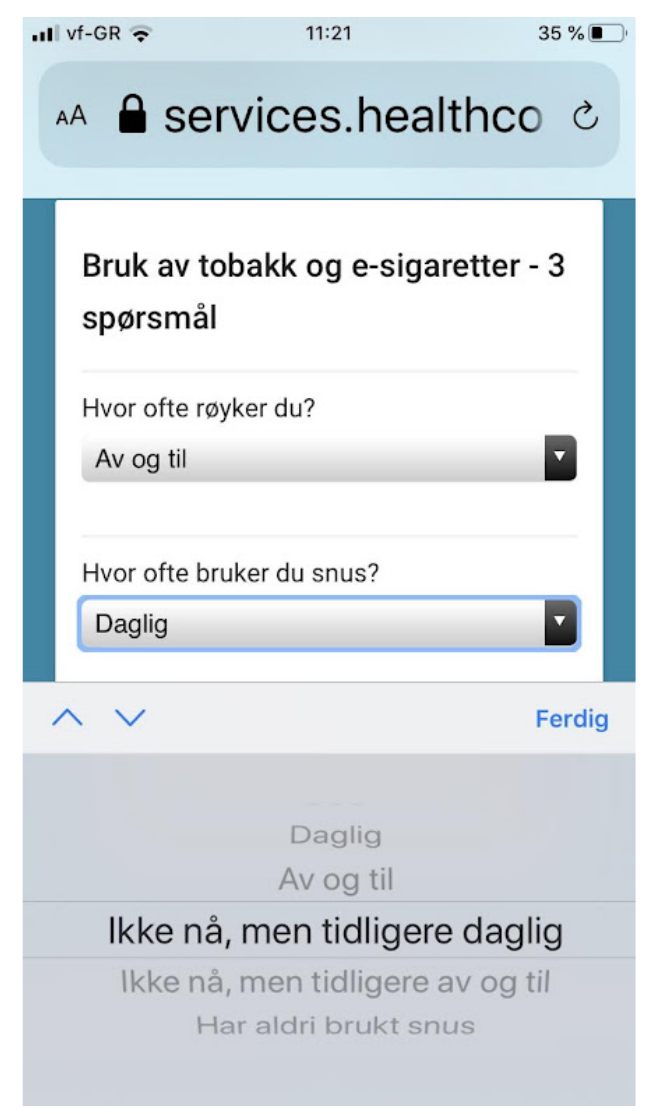

\section{Website}

We developed a website to inform invitees and other interested parties about the study and survey (Figure 4). The website contained information about the background of the study (Figure $5)$, the study population, ethical assessments, survey results (Figure 6), the status of ongoing plans, study funding, and collaborating partners of the study. 
Figure 4. Screenshot of information for invitees.

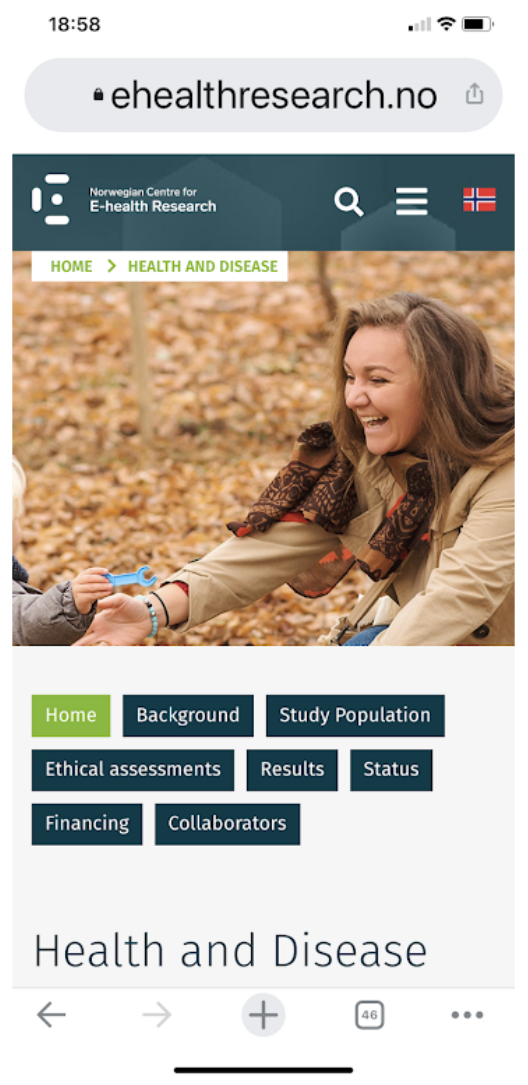

Figure 5. Screenshot of background information.

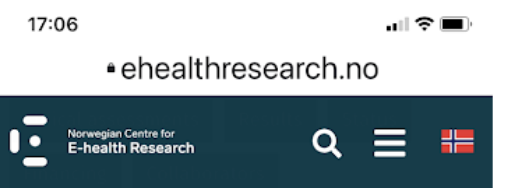

HOME > HEALTH AND DISEASE

Health and Disease

Noncommunicable diseases (NCDs), such as cardiovascular diseases, cancer, chronic respiratory diseases and diabetes, are the leading causes of death in the world. The World Health Assembly has adopted a goal to reduce premature mortality from NCD's by a third (33\%) by 2030, relative to 2015 levels. Norway has endorsed this goal. In order to achieve this goal, we need knowledge about how the prevalence of important lifestyle factors changes in the Norwegian population.

The Health and Disease survey is Norway's first national public health survey that uses digital solutions to gather information on selected lifestyle factors from a random sample of people in all the 11 counties. The lifestyle factors we plan to collect annually are: Diet, physical activity, alcohol and tobacco use. The distribution of the selected lifestyle factors can also predict how mortality from cardiovascular diseases, cancer, chronic respiratory diseases and diabetes will develop in the Norwegian population in the future. 
Figure 6. Screenshot of results presented to users.

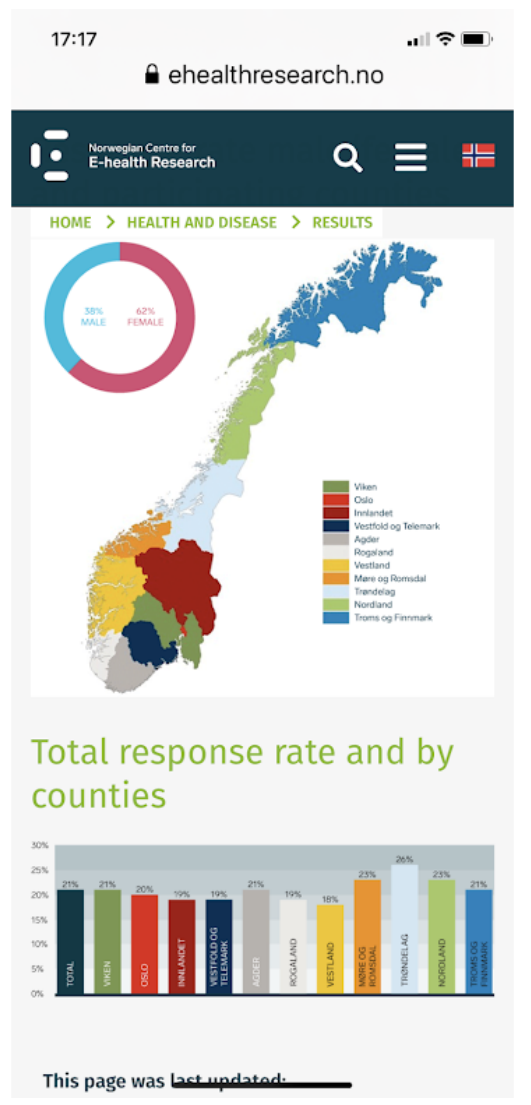

\section{Smartphone Surveys}

\section{Overview}

We designed 2 mobile phone surveys - the first was sent to all invitees (main), and the second was sent only to a random sample of invitees who had not responded to the main survey. A total of 4 sets of SMS messages were sent: 1 request to participate in the main survey, 2 reminders, and 1 request to participate in the second survey (Multimedia Appendix 1). Invitees could obtain additional information when they accessed the survey and the link to the website (Multimedia Appendix 2).

\section{Main Survey}

The survey comprised 26 questions in Norwegian. There were 8 questions on socioeconomic background factors: year of birth, sex, education in years $(\leq 10,11-13,14-16, \geq 17)$, marital status (single, married or cohabitating, divorced, widow or widower), number of persons in the household over and under 18 years $(0,1,2,3, \geq 4)$, gross household income in Norwegian Kroner (1 NOK equals approximately US \$0.11) during the previous year $(\leq 350,000$ NOK, 351,000-550,000 NOK, 551,000-750,000 NOK, 751,000-1,000,000 NOK, $\geq 1,000,000 \mathrm{NOK}$ ), and occupational status (full time work, part-time work, student, retired, home-keeper, military service, and miscellaneous social benefits).

There were 17 questions on the 4 main risk factors. The questionnaire contained 3 questions about cigarette, snus, and e-cigarette use (never, former occasionally, former daily, current occasionally, current daily) and 1 question about alcohol consumption (yes, no). Consumers of alcohol were also asked the first 3 questions from the Alcohol Use Disorders Identification Test [18]—frequency ( $\leq 1$ time per month, 2-4 times per month, 2-3 times per week, $\geq 4$ times per week), number of units usually consumed (1-2, 3-4, 5-6, 7-9, $\geq 10)$, and frequency of occasions of consumption of $\geq 6$ units of alcohol (never, less than monthly, monthly, weekly, daily or almost daily). There were 4 questions related to physical activity from the short version of the International Physical Activity Questionnaire [19]—number of days of strenuous physical activity in the last 7 days $(0,1-2,3-4,5-6,7)$, number of days of moderate physical activity in the last 7 days (0, 1-2, 3-4, 5-6, 7 ), number of days of walking for $\geq 10$ minutes in the last 7 days $(0,1-2,3-4,5-6,7)$, hours spent sitting (excluding sleeping hours) on a regular weekday in the last 7 days (0-2, 3-5, 6-8, $9-11,12-14)$-and 7 questions on dietary intake frequency_-servings per day of fruits and berries $(0,1,2,3,4$, $\geq 5)$, servings per day of lettuce and vegetables $(0,1,2,3,4$, $\geq 5)$, number of glasses per day sugar-sweetened drinks $(0,1$, $2,3,4,5,6, \geq 7)$, number of times fish and fish products are eaten per week $(0,1,2,3,4, \geq 5)$, number of times red meat is eaten per week $(0,1,2,3,4, \geq 5)$, number of times processed meat is eaten per week $(0,1,2,3,4, \geq 5)$, and how often extra salt is added to food before eating (never, occasionally, often, always).

There was 1 question asking if respondents have or have had any of the following conditions: high blood pressure, high cholesterol, atrial fibrillation, myocardial infarction, heart failure, stroke, chronic respiratory disease, cancer, diabetes, or none of these. In addition, there was an open box for comments. 
The estimated time for completing the main survey was approximately 5 minutes.

\section{Second Survey}

The second survey comprised 9 statements that could be answered in the affirmative or negative: "I never answer such surveys"; "I did not want to answer several of the questions"; "I think the questions were difficult to answer"; "I was unsure who the SMS came from"; "I was expecting a login with BankID" (BankID is an electronic identification scheme in Norway for safe log in); "I was afraid that privacy was not taken care of"; "I had not heard of the Norwegian Centre for E-health Research"; "I had not heard of Healthcom"; "I thought the SMS I received looked like spam." The estimated time for completing this survey was approximately 1 minute. There was also an open box for comments.

The main survey was conducted on 11 consecutive days, with 2 reminders sent 5 and 10 days after the original invitation. The second survey was conducted 1 week after the main survey was completed.

\section{Ethics}

The Regional Committee for Medical and Health Research Ethics concluded that approval for this study was not necessary because the study fell outside the Norwegian Health Research Act. The study was approved by the Data Protection Section of the University Hospital of North Norway. All participants provided consented before answering any survey questions.

\section{Recruitment}

A total of 11,000 individuals (an equal number of men and women) aged 16 to 69 years, with 1000 from each of the 11 counties in Norway, were selected randomly from the Norwegian National Population Registry. All Norwegian residents have an 11-digit personal identification number in the National Population Registry. This registry contains the name, address, sex, age, and mobile phone number of each person. Persons who did not have a registered mobile phone number were replaced. For each person, name, personal identification number, phone number, sex, age, year of birth, and county of residence were retained. Subsequently, the system created a unique survey number for each participant. The Data Protection Section of the University Hospital of North Norway provided a server area specifically for this project where the linkage file could be stored. For the second survey, SMS text messages were sent to a random sample of 100 invitees who had not responded to the main survey from each of the 11 counties.

\section{Dissemination}

The communication group at the Norwegian Centre for E-health Research sent a standard press release to each county before the launch of the survey. The press release was followed up with phone contact to selected local media in each county. The communication group used social media (Facebook and Twitter) to promote the survey. Several municipalities informed their residents about the survey on municipality website. The project leader also gave interviews on the local radio and to newspapers in some of the counties. In total, the survey was covered in various media channels 127 times.

\section{Statistical Analysis}

All data used in the analyses, except county of residence, consisted of self-reported data. We calculated means (with standard deviations) or medians (with interquartile range) and percentages for each health variable, overall and by sex, using STATA (version 16.0; Stata Corp).

\section{Results}

\section{Main Survey}

Altogether, 25.2\% $(2769 / 11,000)$ participants opened the survey, while $21.0 \%(2305 / 11,000)$ submitted their responses. We excluded 2 participants reporting to be outside the targeted age groups. The remaining 2303 men and women constituted the respondents to the main survey.

The response rate to the main survey was $21.9 \%$ (2303/11,000; women: 1397/2303, 60.7\%; men: 866/2303, 38.3\%; missing: $40 / 2303,1.7 \%)$. Among men and women, the response rates were $15.7 \%(866 / 5500)$ and $25.4 \%$ (1397/5500), respectively. The median age for men was 52 years (IQR 40-61), and the median age for women was 48 years (IQR 35-58). Trøndelag county had the highest response rate $(26.0 \%, 260 / 1000)$, and Vestland county had the lowest response rates $(18.1 \%$, 181/1000).

Of the 2303 respondents, $1419(61.6 \%)$ answered all the questions; 15 of 29 variables were missing $\leq 3 \%$ values. Each of the questions on socioeconomic background factors had missing values, which ranged from $10.3 \%$ (238/2303) for marital status to $20.6 \%(474 / 2303)$ for number of persons under 18 years old in household. Tobacco and alcohol consumption variables had $\leq 3 \%$ missing values, physical activity variables had $1.8 \%(41 / 2303)$ to $9.7 \%(224 / 2303)$ missing values, and food variables had $1.5 \%(35 / 2303)$ to $5.9 \%$ (136/2303) missing values (Table 1).

Most respondents were in the oldest (50-69 years) age group $(1142 / 2274,50.2 \%)$, in the highest educational category (graduate or postgraduate university education: 1088/1989, $55.1 \%)$, married $(1497 / 2065,73.1 \%$, ), and employed full-time (1158/2015, 57.8\%) (Table 2).

Table 3 shows that $55.4 \%(1225 / 2209)$ of respondents reported being either overweight $(794 / 2209,35.9 \%)$ or obese $(431 / 2209$, $19.5 \%)$, with $63.9 \%(539 / 844)$ of men and $50.3 \%(686 / 1365)$ of women reporting being either overweight or obese.

Daily use of cigarettes (men: 100/855, 11.7\%; women: 140/1380, 10.1\%), snus (men: 153/850, 18.0\%; women: $96 / 1360,7.0 \%)$, and e-cigarettes $(11 / 848,1.3 \%$; women: $19 / 1359,1.4 \%$ ) was reported by respondents, and $32.2 \%$ (237/735) of men reported drinking alcohol more than once a week, of whom $7.1 \%(51 / 724)$ reported consuming $\geq 6$ units on the same occasion weekly, and $22.7 \%$ (254/1119) of women reported drinking alcohol more than once a week, of whom $1.7 \%$ (19/1103) reported consuming $\geq 6$ units on the same occasion weekly. Overall, 17.2\% (378/2199) reported 0 days with moderate physical activity during the last 7 days (Table $3)$. 
Table 4 shows that $38.5 \%(875 / 2268)$ of respondents reported 1 serving per day of fruit and berries, $48.3 \%$ (1091/2255) of respondents reported 1 serving per day of lettuce and vegetables, $67.3 \%(1458 / 2167)$ of respondents reported 0 glasses of sugary drinks per day, $56.6 \%(1233 / 2178)$ of respondents reported $\geq 2$ meals with fish or fish products per week, 67.6\% (1465/2167) of respondents reported $\leq 2$ meals of red meat per week, and $23.5 \%(517 / 2198)$ of respondents reported never adding extra salt before eating.

Only 44.5\% (984/2209) of respondents were in line with national recommendations for BMI, and 42.0\% (932/2219) of respondents were in line with national recommendations for tobacco or e-cigarette use [20]; $81.2 \%$ (1501/1848) were in line with national recommendations for alcohol consumption (ie, consuming $\geq 6$ units of alcohol on one occasion less than monthly or never [21]). Only $34.2 \%$ (704/2056) of respondents met national recommendations for physical activity levels (ie, walking $\geq 10$ minutes every day the last 7 days [22]), and only $22.9 \%(522 / 2281)$ of respondents met national recommendations for eating fruits and vegetables (ie, at least 5 servings per day [23]).

Table 1. Overall respondents and missing values to the main smartphone survey.

\begin{tabular}{|c|c|c|}
\hline Variable & Respondents, $\mathrm{N}$ & Missing, $\mathrm{n}(\%)$ \\
\hline Age & 2274 & $29(1.3)$ \\
\hline Sex & 2263 & $40(1.7)$ \\
\hline Education & 1989 & $314(13.6)$ \\
\hline Marital status & 2065 & $238(10.3)$ \\
\hline Number of persons ( $>18$ years old) in household & 1914 & $389(16.9)$ \\
\hline Number of persons ( $<18$ years old) in household & 1829 & $474(20.6)$ \\
\hline Gross household income 2018 & 1946 & $357(15.5)$ \\
\hline Work life condition/occupation & 2015 & $288(12.5)$ \\
\hline Chronic disease conditions (noncommunicable disease) & 2245 & $58(2.5)$ \\
\hline Height & 2270 & $33(1.4)$ \\
\hline Weight & 2247 & $56(2.4)$ \\
\hline $\mathrm{BMI}^{\mathrm{a}}$ & 2237 & $66(2.9)$ \\
\hline Smoking history & 2261 & $42(1.8)$ \\
\hline Snus use history & 2245 & $58(2.5)$ \\
\hline E-cigarette use history & 2234 & $69(3.0)$ \\
\hline Alcohol consumption (yes/no) & 2284 & $19(0.8)$ \\
\hline Frequency of alcohol consumption ${ }^{b}$ & 1876 & $29(1.5)$ \\
\hline Units of alcohol usually consumed ${ }^{b}$ & 1868 & $37(1.9)$ \\
\hline Frequency of occasions of consumption of $\geq 6$ units of alcohol ${ }^{b}$ & 1848 & $57(3.0)$ \\
\hline Number of days of strenuous physical activity in the last 7 days & 2262 & $41(1.8)$ \\
\hline Number of days of moderate physical activity in the last 7 days & 2199 & $104(4.5)$ \\
\hline Number of days of walking for $\geq 10$ minutes in the last 7 days & 2079 & $224(9.7)$ \\
\hline Hours spent sitting on a regular weekday in the last 7 days (excluding sleeping hours) & 2166 & $137(6.0)$ \\
\hline Fruits and berries intake (servings) per day & 2268 & $35(1.5)$ \\
\hline Lettuce and vegetable intake (servings) per day & 2255 & $48(2.1)$ \\
\hline Sugary drinks, number of glasses per day & 2167 & $136(5.9)$ \\
\hline Fish and fish products, number of times eaten per week & 2178 & $125(5.4)$ \\
\hline Red meat, number of times eaten per week & 2167 & $136(5.9)$ \\
\hline Processed meat, number of times eaten per week & 2167 & $136(5.9)$ \\
\hline Addition of extra salt to food & 2198 & $105(4.6)$ \\
\hline
\end{tabular}

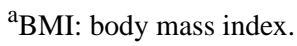

${ }^{\mathrm{b}}$ Among 1905 participants who responded yes to alcohol consumption. 
Table 2. Respondents' background characteristics (overall and by sex).

\begin{tabular}{|c|c|c|c|}
\hline Characteristic & All, n $(\%)^{\mathrm{a}}$ & Men, n (\%) & Women, $\mathrm{n}(\%)^{\mathrm{a}}$ \\
\hline \multicolumn{4}{|l|}{ Age groups (years) } \\
\hline $16-29$ & $347(15.4)$ & $121(14.0)$ & $226(16.3)$ \\
\hline $30-49$ & $760(33.8)$ & $264(30.7)$ & $496(35.7)$ \\
\hline $50-69$ & $1142(50.8)$ & $476(55.3)$ & $666(48.0)$ \\
\hline \multicolumn{4}{|l|}{ Education (number of years) } \\
\hline$\leq 10$ (primary school) & $219(11.1)$ & $104(13.6)$ & $115(9.5)$ \\
\hline 11-13 (high school) & $666(33.8)$ & $290(37.8)$ & $376(31.2)$ \\
\hline 14-16 (graduate) & $508(25.7)$ & $180(23.5)$ & $328(27.2)$ \\
\hline$\geq 17$ (postgraduate) & $580(29.4)$ & $193(25.2)$ & $387(32.1)$ \\
\hline \multicolumn{4}{|l|}{ Marital status } \\
\hline Single & $389(19.0)$ & $155(19.7)$ & 234 (18.6) \\
\hline Married or cohabitating & $1497(73.1)$ & $575(73.1)$ & $922(73.1)$ \\
\hline Divorced & $126(6.1)$ & $48(6.1)$ & $78(6.2)$ \\
\hline Widow or widower & $36(1.8)$ & $9(1.1)$ & $27(2.1)$ \\
\hline \multicolumn{4}{|c|}{ Number of adults (age $\geq 18$ years) in household } \\
\hline 0 & $151(7.5)$ & $57(7.3)$ & $94(7.7)$ \\
\hline 1 & $474(23.6)$ & $184(23.7)$ & $290(23.6)$ \\
\hline 2 & $1013(50.5)$ & $383(49.3)$ & $630(51.3)$ \\
\hline 3 & $230(11.5)$ & $93(12.0)$ & $137(11.2)$ \\
\hline$\geq 4$ & $137(6.8)$ & $60(7.7)$ & $77(6.3)$ \\
\hline \multicolumn{4}{|c|}{ Number of children (age $<18$ years) in household } \\
\hline 0 & $1180(61.6)$ & $482(65.1)$ & $698(59.4)$ \\
\hline 1 & $293(15.3)$ & $95(12.8)$ & $198(16.8)$ \\
\hline 2 & $305(15.9)$ & $115(15.5)$ & $190(16.2)$ \\
\hline 3 & $106(5.5)$ & $40(5.4)$ & $66(5.6)$ \\
\hline$\geq 4$ & $32(1.7)$ & $9(1.2)$ & $23(2.0)$ \\
\hline \multicolumn{4}{|c|}{ Gross household income in 2018 (in Norwegian Kroner) } \\
\hline$\leq 350,000$ & $249(12.9)$ & $80(10.7)$ & $169(14.3)$ \\
\hline $351,000-550,000$ & $342(17.7)$ & $117(15.6)$ & $225(19.0)$ \\
\hline $551,000-750,000$ & $316(16.4)$ & $118(15.8)$ & $198(16.7)$ \\
\hline $751,000-1,000,000$ & $430(22.2)$ & $177(23.7)$ & $253(21.4)$ \\
\hline$>1,000,000$ & $595(30.8)$ & $256(34.2)$ & $339(28.6)$ \\
\hline \multicolumn{4}{|l|}{ Occupational status } \\
\hline Full-time work & $1158(57.9)$ & $524(68.1)$ & $634(51.5)$ \\
\hline Part-time work & $234(11.7)$ & $37(4.8)$ & $197(16.0)$ \\
\hline Student & $146(7.3)$ & $50(6.5)$ & $96(7.8)$ \\
\hline Retired & $180(9.0)$ & $76(9.9)$ & $104(8.5)$ \\
\hline Other ${ }^{b}$ & $281(14.1)$ & $82(10.7)$ & $199(16.2)$ \\
\hline
\end{tabular}

${ }^{\mathrm{a}}$ Missing responses were not included in calculated percentages.

${ }^{\mathrm{b}}$ Home-keeper, military service, and miscellaneous benefits (sick leave, unemployment, disabilities, social security). 
Table 3. Respondents' lifestyle factors (overall and by sex).

\begin{tabular}{|c|c|c|c|}
\hline Factor & All, $\mathrm{n}(\%)^{\mathrm{a}}$ & Men, n $(\%)^{\mathrm{a}}$ & Women, $\mathrm{n}(\%)^{\mathrm{a}}$ \\
\hline \multicolumn{4}{|l|}{$\operatorname{BMI}^{\mathrm{b}}\left(\mathrm{kg} / \mathrm{m}^{2}\right)$} \\
\hline$<18.5$ & $29(1.3)$ & $3(0.4)$ & $26(1.9)$ \\
\hline $18.5-24.9$ & $955(43.2)$ & $302(35.8)$ & $653(47.8)$ \\
\hline $25.0-29.9$ & $794(35.9)$ & $367(43.5)$ & $427(31.3)$ \\
\hline$\geq 30.0$ & $431(19.5)$ & $172(20.4)$ & $259(19.0)$ \\
\hline \multicolumn{4}{|l|}{ Smoking history } \\
\hline Never & $1087(48.6)$ & $392(45.9)$ & $695(50.4)$ \\
\hline Former occasionally & $344(15.4)$ & $125(14.6)$ & $219(15.9)$ \\
\hline Former daily & $469(21.0)$ & $201(23.5)$ & $268(19.4)$ \\
\hline Current occasionally & $95(4.3)$ & $37(4.3)$ & $58(4.2)$ \\
\hline Current daily & $240(10.7)$ & $100(11.7)$ & $140(10.1)$ \\
\hline \multicolumn{4}{|l|}{ Snus use history } \\
\hline Never & $1726(77.8)$ & $571(67.2)$ & $1155(84.4)$ \\
\hline Former occasionally & $97(4.4)$ & $51(6.0)$ & $46(3.4)$ \\
\hline Former daily & $80(3.6)$ & $51(6.0)$ & $29(2.1)$ \\
\hline Current occasionally & $66(3.0)$ & $24(2.8)$ & $42(3.1)$ \\
\hline Current daily & $249(11.2)$ & $153(18.0)$ & $96(7.0)$ \\
\hline \multicolumn{4}{|l|}{ E-cigarette use history } \\
\hline Never & 2069 (93.7) & $786(92.7)$ & $1283(94.4)$ \\
\hline Former occasionally & $66(3.0)$ & $27(3.2)$ & $39(2.9)$ \\
\hline Former daily & $15(0.7)$ & $10(1.2)$ & $5(0.4)$ \\
\hline Current occasionally & $27(1.2)$ & $14(1.7)$ & $13(1.0)$ \\
\hline Current daily & $30(1.4)$ & $11(1.3)$ & $19(1.4)$ \\
\hline \multicolumn{4}{|l|}{ Alcohol consumption } \\
\hline No & $376(16.7)$ & $120(13.9)$ & $256(18.4)$ \\
\hline Yes & $1880(83.3)$ & $743(86.1)$ & $1137(81.6)$ \\
\hline \multicolumn{4}{|l|}{ Frequency } \\
\hline$\leq 1$ time per month & $493(26.6)$ & $149(20.3)$ & $344(30.7)$ \\
\hline 2-4 times per month & $870(46.9)$ & $349(47.5)$ & $521(46.6)$ \\
\hline 2-3 times per week & $402(21.7)$ & $191(26.0)$ & $211(18.9)$ \\
\hline$\geq 4$ times per week & $89(4.8)$ & $46(6.3)$ & $43(3.8)$ \\
\hline \multicolumn{4}{|l|}{ Units usually consumed } \\
\hline $1-2$ & $994(53.8)$ & $366(49.7)$ & $628(56.6)$ \\
\hline $3-4$ & $538(29.1)$ & $215(29.2)$ & $323(29.1)$ \\
\hline $5-6$ & $208(11.3)$ & $86(11.7)$ & $122(11.0)$ \\
\hline $7-9$ & $84(4.6)$ & $56(7.6)$ & $28(2.5)$ \\
\hline$\geq 10$ & $22(1.2)$ & $14(1.9)$ & $8(0.7)$ \\
\hline \multicolumn{4}{|c|}{ Frequency of occasions with $\geq 6$ units consumed } \\
\hline Never & $545(29.5)$ & $132(18.2)$ & $403(36.5)$ \\
\hline Less than monthly & $956(51.7)$ & $385(53.2)$ & $561(50.9)$ \\
\hline Monthly & $277(15.0)$ & $156(21.6)$ & $120(10.9)$ \\
\hline
\end{tabular}




\begin{tabular}{lllll}
\hline Factor & & All, $\mathrm{n}(\%)^{\mathrm{a}}$ & Men, $\mathrm{n}(\%)^{\mathrm{a}}$ & Women, $\mathrm{n}(\%)^{\mathrm{a}}$ \\
\hline \multirow{2}{*}{ Weekly } & $68(3.7)$ & $49(6.8)$ & $19(1.7)$ \\
& Daily or almost daily & $2(0.1)$ & $2(0.3)$ & $(0.0)$
\end{tabular}

Days with strenuous physical activity in the last 7 days

0
$1-2$
$3-4$
$5-6$
7

$\begin{array}{lll}639(28.6) & 198(23.2) & 441(32.0) \\ 828(37.1) & 308(36.0) & 520(37.7) \\ 527(23.6) & 228(26.7) & 299(21.7) \\ 180(8.0) & 9(10.5) & 90(6.5) \\ 61(2.7) & 31(3.6) & 30(2.2)\end{array}$

Days with moderate physical activity in the last 7 days

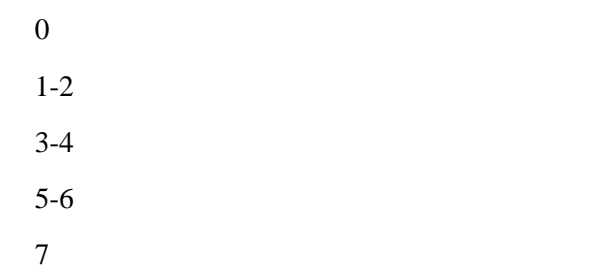

$378(17.4)$
$927(42.6)$
$510(23.5)$
$227(10.4)$
$133(6.1)$

$\begin{array}{ll}133(16.0) & 245(18.2) \\ 350(42.1) & 577(42.9) \\ 187(22.5) & 323(24.0) \\ 108(13.0) & 119(8.8) \\ 53(6.4) & 80(6.0)\end{array}$

Days walking for $\geq 10$ minutes in the last 7 days

0
$1-2$
$3-4$
$5-6$
7

$99(4.8)$
$373(18.1)$
$480(23.4)$
$400(19.5)$
$704(34.2)$

$\begin{array}{ll}55(7.1) & 44(3.4) \\ 154(19.7) & 219(17.2) \\ 189(24.2) & 291(22.8) \\ 153(19.6) & 247(19.4) \\ 229(29.4) & 475(37.2)\end{array}$

Hours spent sitting on a regular weekday in the last 7 days (excluding sleeping hours)

$\begin{array}{llll}0-2 & 162(7.6) & 58(7.1) & 104(7.9) \\ 3-5 & 876(40.9) & 292(35.5) & 584(44.3) \\ 6-8 & 598(27.9) & 245(29.8) & 353(26.7) \\ 9-11 & 348(16.3) & 150(18.2) & 198(15.0) \\ 12-14 & 109(5.1) & 59(7.2) & 50(3.8) \\ \geq 15 & 48(2.2) & 18(2.2) & 30(2.3)\end{array}$

${ }^{\mathrm{a}}$ Missing responses were not included in calculated percentages.

${ }^{\mathrm{b}} \mathrm{BMI}$ : body mass index. 
Table 4. Respondents' dietary intake variables (overall and by sex).

\begin{tabular}{|c|c|c|c|}
\hline Variable & All, $\mathrm{n}(\%)^{\mathrm{a}}$ & Men, $\mathrm{n}(\%)^{\mathrm{a}}$ & Women, $\mathrm{n}(\%)^{\mathrm{a}}$ \\
\hline \multicolumn{4}{|c|}{ Fruits and berries (servings per day) } \\
\hline 0 & $260(11.6)$ & $136(15.8)$ & $124(9.0)$ \\
\hline 1 & $875(39.1)$ & $378(44.1)$ & $497(35.9)$ \\
\hline 2 & $621(27.7)$ & $205(23.9)$ & $416(30.1)$ \\
\hline 3 & $309(13.8)$ & $93(10.8)$ & $216(15.6)$ \\
\hline 4 & $99(4.4)$ & $25(2.9)$ & $74(5.4)$ \\
\hline$\geq 5$ & $77(3.4)$ & $21(2.5)$ & $56(4.0)$ \\
\hline \multicolumn{4}{|c|}{ Lettuce and vegetables (servings per day) } \\
\hline 0 & $134(6.0)$ & $82(9.6)$ & $52(3.8)$ \\
\hline 1 & $1091(49.0)$ & $494(58.1)$ & $597(43.3)$ \\
\hline 2 & $643(28.9)$ & $190(22.4)$ & $453(32.9)$ \\
\hline 3 & $225(10.1)$ & $50(5.9)$ & $175(12.7)$ \\
\hline 4 & $72(3.2)$ & $19(2.2)$ & $53(3.8)$ \\
\hline$\geq 5$ & $63(2.8)$ & $15(1.8)$ & $48(3.5)$ \\
\hline \multicolumn{4}{|c|}{ Sugary drinks (glasses per day) } \\
\hline 0 & $1458(68.1)$ & $497(60.7)$ & $961(72.7)$ \\
\hline 1 & $415(19.4)$ & $192(23.4)$ & $223(16.9)$ \\
\hline 2 & $134(6.3)$ & $67(8.2)$ & $67(5.1)$ \\
\hline 3 & $60(2.8)$ & $28(3.4)$ & $32(2.4)$ \\
\hline 4 & $26(1.2)$ & $10(1.2)$ & $16(1.2)$ \\
\hline$\geq 5$ & $47(2.2)$ & $25(3.1)$ & $22(1.7)$ \\
\hline \multicolumn{4}{|c|}{ Fish and fish products (number of times eaten per week) } \\
\hline 0 & $151(7.0)$ & $48(5.8)$ & $103(7.7)$ \\
\hline 1 & $769(35.7)$ & $293(35.6)$ & $476(35.8)$ \\
\hline 2 & $789(36.7)$ & $312(38.0)$ & $477(35.8)$ \\
\hline 3 & $339(15.7)$ & $136(16.6)$ & $203(15.3)$ \\
\hline 4 & $82(3.8)$ & $28(3.4)$ & $54(4.1)$ \\
\hline$\geq 5$ & $23(1.1)$ & $5(0.6)$ & $18(1.3)$ \\
\hline \multicolumn{4}{|c|}{ Red meat (number of times eaten per week) } \\
\hline 0 & $172(8.0)$ & $37(4.5)$ & $135(10.3)$ \\
\hline 1 & $664(31.0)$ & $241(29.3)$ & $423(32.1)$ \\
\hline 2 & $629(29.4)$ & $255(31.0)$ & $374(28.4)$ \\
\hline 3 & $369(17.2)$ & $163(19.8)$ & $206(15.6)$ \\
\hline 4 & $179(8.4)$ & $78(9.5)$ & $101(7.7)$ \\
\hline$\geq 5$ & $127(5.9)$ & $49(5.9)$ & $78(5.9)$ \\
\hline \multicolumn{4}{|c|}{ Processed meat (number of times eaten per week) } \\
\hline 0 & $341(15.9)$ & $96(11.7)$ & $245(18.6)$ \\
\hline 1 & $868(40.6)$ & $328(39.9)$ & $540(40.9)$ \\
\hline 2 & $581(27.2)$ & $230(28.0)$ & $351(26.6)$ \\
\hline 3 & $266(12.4)$ & $127(15.5)$ & $139(10.5)$ \\
\hline 4 & $51(2.4)$ & $27(3.3)$ & $24(1.8)$ \\
\hline$\geq 5$ & $33(1.5)$ & $13(1.6)$ & $20(1.5)$ \\
\hline
\end{tabular}




\begin{tabular}{llll}
\hline Variable & All, $\mathrm{n}(\%)^{\mathrm{a}}$ & Men, $\mathrm{n}(\%)^{\mathrm{a}}$ & Women, $\mathrm{n}(\%)^{\mathrm{a}}$ \\
\hline Addition of extra salt to food & & & \\
$\quad$ Never & $517(23.8)$ & $192(23.2)$ & $325(24.2)$ \\
Occasionally & $1264(58.2)$ & $465(56.1)$ & $799(59.5)$ \\
Often & $306(14.1)$ & $127(15.3)$ & $179(13.3)$ \\
Always & $84(3.9)$ & $45(5.4)$ & $39(2.9)$ \\
\hline
\end{tabular}

${ }^{\mathrm{a}}$ Missing responses were not included in calculated percentages.

\section{Second Survey}

Altogether, $18.1 \%(199 / 1100)$ of the invitees to the second survey opened it, but $8.2 \%$ (90/1100) did not submit a response, while $9.9 \%$ (109/1100) replied to some or all and submitted their answers. The latter group constituted the respondents of the second survey. The most common reason for not participating (in the main survey) was "I had not heard of Healthcom" (yes: 43/109, 39.4\%; no: 10/109, 9.2\%; missing: $56 / 109,49.5 \%$ ), followed by both "I had not heard of the National Center for E-Health Research" and "I was unsure who the SMS came from" (yes: 37/109, 33.9\%; no: 11/109, 10.1\%; missing: 61/109, 56.0\%), then "I thought the SMS I received looked like spam" (yes: 35/109, 32.1\%; no: 10/109, 9.2\%; missing: 64/109, 58.7\%).

\section{Discussion}

\section{Principal Results}

This feasibility study is, to the best of our knowledge, the first successfully piloted smartphone-based information communication technology solution with technically, ethically, and regulatory functionalities for collecting annual data on the 4 main modifiable risk factors for the 4 main noncommunicable diseases. The primary reason reported for not participating in the initial survey was that the sender of the SMS was unknown. Due to the differences in response rates between men and women and between counties, our secondary objective to collect nationally representative data may not have been achieved. If the respondent sample has a similar distribution with respect to background characteristics, life style factors, and dietary intake variables, they may be nationally representative regardless of response rate.

\section{Comparison With Past Work}

We are not aware of any previous work with the same overall objectives as ours.

We chose to use SMS text messaging as the means of initial contact, instead of internet or email surveys, ordinary or computer-assisted telephone interviews, or interactive voice response because text messages are often perceived as personal forms of communication; they are more likely to be read quickly, understood, and responded to upon receipt [24]; and they are relatively cheap, with high reachability because mobile phones are ubiquitous. We anticipated that SMS text messaging would allow simple, low-commitment participation in the survey. We considered the intrusiveness (or push factor) to be an advantage; however, one disadvantage is that messages are limited to 160 characters, after which additional payments fare required for every 160 characters. Our request to participate had many more characters; therefore, we had to pay 3 times the ordinary amount for each message. Another disadvantage is that more and more commercial organizations have started using SMS text messages for customer satisfaction surveys. This can lead to an overload of text messages considered to be spam.

In 2017, Pariyo et al [25] suggested that mobile phone surveys have the potential to become a powerful data collection tool to address public health challenges, such as those arising from noncommunicable diseases, in low- and middle-income countries. Ethical considerations in global mobile phone-based surveys of noncommunicable diseases have also recently been discussed, and a need for a broad conceptual framework for the ethical, legal, and societal issues associated with mobile phone surveys for noncommunicable disease risk factors was identified [26].

\section{Response Rate}

In addition to randomized selection of participants, response rate is often considered to be an important factor in obtaining representative data. Our response rate $(2305 / 11,000,21.0 \%)$ was similar to those of 2 Norwegian eHealth research studies-a large population-based randomized controlled trial on smoking cessation with SMS text messaging or emails [27] and a web-based cross-sectional survey on diabetes [28]. We are satisfied that we achieved a response rate from the general population that was similar to that in these 2 surveys, which both had highly selected participants.

It is common for researchers to use monetary incentives (such as gift certificates or lottery tickets) to increase participation [29-31]. Instead of monetary incentives, we had intended to develop personalized feedback, based on national guidelines, for respondents. Though part of this feature was developed, due to time, monetary, and personnel constraints, we were not able to create detailed personalized responses for all possible combinations of answers to the survey. Since we did not complete this, the invitees were not informed about or given any options for personalized feedback. Most importantly, we were not able to examine if this would be an incentive to respond to the survey.

There is, as far as we know, no commonly accepted minimal response rate. In the UK Biobank cohort [32], there were close to 10 million invitees and the response rate was $5.45 \%$. A response rate of $60 \%$ has been used as the threshold of acceptability for population-based face-to-face or postal surveys; however, this response rate can also cover up response bias [33] 
if the characteristics of nonrespondents differ from those of the respondents. However, if respondents are perfectly representative of the source population, a low response rate is not a problem. [33]. Low participation, high dropout, or high loss to follow-up may be expected features of eHealth research and likely should not be looked upon as failures [34].

We assume that our response rate would have been higher if our university, a renowned entity, had been the sender. Instead, the Norwegian Centre for E-health Research, which was established in 2016 (a few years before the survey), and Healthcom both appeared as senders of the initial SMS. A systematic review [35] found that response rates for paper questionnaires were higher if they originated from universities rather than from other sources such as commercial organizations. We have previously found that more specific titles to otherwise identical questionnaires influenced the response rate of mailed surveys [36]; therefore, in addition, the name of the survey — Health and Disease - was too general.

Another Norwegian eHealth study [37], which examined recruitment to public health surveys with electronic forms on 2 different platforms, found that (1) sampling from the national health website (30 000 invitees) yielded a response rate of $40.8 \%$, whereas sampling from the National Population Registry (36 000 invitees) yielded a response rate of $41.5 \%$ and (2) there were systematic and pronounced differences in the responses of the 2 samples. Skogen et al [37] concluded that limiting recruitment to users of Helsenorge (Health Norway) services resulted in further selection problems.

Our survey was conducted in 2019 (before the COVID-19 pandemic) in Norway, and approximately 1 in 5 respondents $(431 / 2209,19.5 \%)$ reported being obese. In fall 2020, after the first national lockdown, the Norwegian Institute of Public Health conducted a pilot study, collecting data on risk factors for the 4 main noncommunicable diseases and several other topics [38], which noted as a limitation, that most questions in the survey had not yet been validated, but that this would be done at a later stage. As we did, they randomly sampled from each of the 11 counties, but they invited twice as many from each county and used both email and SMS text messaging to contact the invitees. The response rate to this survey [38] was $38.1 \%$, and $16 \%$ of respondents reported being obese, and $59 \%$ of the men and $47 \%$ of the women reported being overweight or obese. We do not have a good explanation why we found greater percentages - 63.9\% (539/844) of men and 50.3\% (686/1365) of women reporting being either overweight or obese.

Similar to our findings, (1) the 3 previously described eHealth studies $[27,28,38]$ found that more women than men responded, and (2) the 2020 national survey [37] found that Trøndelag county had the highest response rate. One reason may be that the people residing in Trøndelag have been invited 4 times to the Trøndelag Health Study [11], which collected health survey data from the same geographic population [39].

In our survey, $10.7 \%$ (240/2235) reported smoking daily. For 2019, Statistics Norway reported overall daily smoking to be $9 \%$ for both sexes [40]. The proportion of men who reported being daily snus use in our study $(153 / 850,18.0 \%)$ was a little lower than that found by Statistics Norway in 2019 (20\% [40]), while the proportion of women found by Statistics Norway (7\% [40]) was the same as that found in our study $(96 / 1368,7.0 \%)$.

In our survey, $32.3 \%$ (237/735) men reported drinking alcohol more than once a week; the corresponding figure for Statistics Norway survey was $34 \%$. In our survey, $7 \%$ (51/724) of men reported having consumed more than 6 units on the same occasion weekly; the corresponding figure for the 2019 Statistics Norway survey was 5\%. In our survey, 23\% (254/1119) of women reported drinking alcohol more than once a week; the corresponding figure for the 2019 Statistics Norway survey was $28 \%$. In our survey, less than $2 \%$ reported having consumed more than 6 units on the same occasion weekly; the corresponding figure for the 2019 Statistics Norway survey was $3 \%$.

A recent review [41] found that pilot or feasibility studies are still poorly reported, and only $8.9 \%$ of the 90 studies led to subsequent main studies. This study will continue to be developed as part of a larger project [42].

\section{Strengths}

For a nationally representative study population, participants were sampled randomly from each of the 11 counties. Major assets were that our main survey could be answered in 5 minutes and comprised already validated questions.

\section{Limitations}

The main limitation of our study was the low response rate. Other limitations include the use of self-reported information and that only individuals who had a smartphone could participate; however, since smartphone ownership exceeds $80 \%$ in Norway [14], not being eligible due to not having a smartphone is a minor concern. This may be a concern in other countries.

\section{Implications for Future Research}

Short smartphone surveys have the potential to be used to monitor trends annually to identify high-risk groups for the 4 main noncommunicable diseases. This knowledge can subsequently be used for better targeting of interventions and in policy making, to meet the United Nations Sustainable Development Goal to reduce premature mortality from noncommunicable diseases by $33 \%$ by 2030 [4].

We encourage the further study of short mobile phone-based surveys regarding the modifiable risk factors for the 4 main noncommunicable diseases in high-, low-, and middle-income countries. Our study included only Norwegians, of whom the majority had more than high school level of education. Future studies should develop surveys that are easily recognized as research, have a well-known sender, and can be distinguished from spam. We recommend examining if an offer to the invitees for personalized feedback in response to their answers about the modifiable risk factors will increase overall participation.

\section{Conclusions}

We successfully developed and piloted a smartphone-based information communication technology solution for collecting data annually on the four modifiable risk factors for the 4 main noncommunicable disease from a random sample of the 
Norwegian population; 1 in 5 responded, thus our secondary been achieved. objective to collect nationally representative data may not have

\section{Acknowledgments}

The project was funded in part by the Research Council of Norway (HELSE-EU-project 269882).

We would like to thank all the participants in the Health and Disease survey. We would also like to thank Niels Frost, at Healthcom, and Jarl-Stian Olsen, for designing the Norwegian and English websites and the poster, and Lene Lundberg and Randi Laukli, for their efforts to promote the main survey on social and other media, at the Norwegian Centre for E-health Research.

\section{Authors' Contributions}

ITG conceived the idea. ITG, GS, LAH, KBB, and MLL designed and conducted the study. SOO and ITG performed analyses. ITG drafted the manuscript. All authors contributed to interpreting the data, drafting the manuscript, and critically revising the manuscript for important intellectual content.

\section{Conflicts of Interest}

None declared.

\section{Multimedia Appendix 1}

SMS text message request to participate in main and second survey.

[DOCX File, 15 KB-Multimedia Appendix 1]

\section{Multimedia Appendix 2}

Additional information given to the invitees after accessing the survey.

[DOCX File, $14 \mathrm{~KB}$-Multimedia Appendix 2]

\section{References}

1. Noncommunicable diseases 2018. World Health Organization (WHO) 2018. URL: https://www.who.int/health-topics/ noncommunicable-diseases\#tab=tab 1 [accessed 2021-02-05]

2. NCD Countdown 2030 collaborators. NCD Countdown 2030: worldwide trends in non-communicable disease mortality and progress towards Sustainable Development Goal target 3.4. Lancet 2018 Sep 22;392(10152):1072-1088. [doi: 10.1016/S0140-6736(18)31992-5] [Medline: 30264707]

3. NCD Countdown 2030 collaborators. NCD Countdown 2030: pathways to achieving sustainable development goal target 3.4. Lancet 2020 Sep 26;396(10255):918-934 [FREE Full text] [doi: 10.1016/S0140-6736(20)31761-X] [Medline: 32891217 ]

4. Transforming our world: the 2030 agenda for sustainable development 2020. United Nations. 2020. URL: https://sdgs. un.org/2030agenda [accessed 2021-02-05]

5. World cancer report: cancer research for cancer prevention 2020. International Agency for Research on Cancer. URL: https://www.iccp-portal.org/system/files/resources/IARC\%20World\%20Cancer\%20Report\%202020.pdf [accessed 2021-05-29]

6. Riley L, Guthold R, Cowan M, Savin S, Bhatti L, Armstrong T, et al. The World Health Organization STEPwise approach to noncommunicable disease risk-factor surveillance: methods, challenges, and opportunities. Am J Public Health 2016 Jan;106(1):74-78. [doi: 10.2105/AJPH.2015.302962] [Medline: 26696288]

7. STEPwise Approach to NCD risk factor surveillance. World Health Organization. URL: https://www.who.int/teams/ noncommunicable-diseases/surveillance/systems-tools/steps [accessed 2021-05-30]

8. Tobacco, alcohol and other drugs 2021. Statistics Norway. URL: https://www.ssb.no/en/helse/helseforhold-og-levevaner/ statistikk/royk-alkohol-og-andre-rusmidler [accessed 2021-05-30]

9. Norkost 4 is a dietary survey where a representative sample of the adult Norwegian population aged 18-80 years is invited to participate. Norkost 4. 2022 May 01. URL: https://www.med.uio.no/imb/english/research/projects/norkost/index.html [accessed 2021-10-05]

10. Statistikk om fysisk aktivitetsnivå og stillesitting [Statistics on physical activity level and sitting still]. Helsedirektoratet. URL: https://www.helsedirektoratet.no/tema/fysisk-aktivitet/statistikk-om-fysisk-aktivitetsniva-og-stillesitting [accessed 2021-09-20]

11. Krokstad S, Langhammer A, Hveem K, Holmen TL, Midthjell K, Stene TR, et al. Cohort profile: the HUNT study, Norway. Int J Epidemiol 2013 Aug;42(4):968-977. [doi: 10.1093/ije/dys095] [Medline: 22879362]

12. Jacobsen BK, Eggen AE, Mathiesen EB, Wilsgaard T, Njølstad I. Cohort profile: the Tromso study. Int J Epidemiol 2012 Aug;41(4):961-967 [FRE Full text] [doi: 10.1093/ije/dyr049] [Medline: 21422063] 
13. Lov om folkehelsearbeid (folkehelseloven). Lovdata. URL: https://lovdata.no/dokument/NL/lov/2011-06-24-29/ KAPITTEL 2\#\%C2\%A75 [accessed 2022-02-01]

14. ICT usage in households 2021. Statistics Norway. URL: https://www.ssb.no/en/statbank/table/12344 [accessed 2021-10-14]

15. Lov om behandling av personopplysninger (personopplysningsloven). Lovdata. URL: https://lovdata.no/dokument/NL/lov/ 2018-06-15-38 [accessed 2022-02-09]

16. Harris PA, Taylor R, Thielke R, Payne J, Gonzalez N, Conde JG. Research electronic data capture (REDCap)--a metadata-driven methodology and workflow process for providing translational research informatics support. J Biomed Inform 2009 Apr;42(2):377-381 [FREE Full text] [doi: 10.1016/j.jbi.2008.08.010] [Medline: 18929686]

17. Harris PA, Taylor R, Minor BL, Elliott V, Fernandez M, O'Neal L, REDCap Consortium. The REDCap consortium: building an international community of software platform partners. J Biomed Inform 2020 Jul 1;95:103208 [FREE Full text] [doi: 10.1016/j.jbi.2019.103208] [Medline: $\underline{\text { 31078660] }}$

18. Bohn MJ, Babor TF, Kranzler HR. The alcohol use disorders identification test (AUDIT): validation of a screening instrument for use in medical settings. J Stud Alcohol 1995 Jul;56(4):423-432. [Medline: 7674678]

19. Cleland C, Ferguson S, Ellis G, Hunter RF. Validity of the international physical activity questionnaire (IPAQ) for assessing moderate-to-vigorous physical activity and sedentary behaviour of older adults in the United Kingdom. BMC Med Res Methodol 2018 Dec 22;18(1):176 [FREE Full text] [doi: 10.1186/s12874-018-0642-3] [Medline: $\underline{30577770]}$

20. Tobacco control in Norway. The Norwegian Directorate of Health. URL: https://www.helsedirektoratet.no/english/ tobacco-control-in-norway [accessed 2022-02-10]

21. Nasjonal alkoholstrategi. Regjeringen. URL: https://www.regjeringen.no/contentassets/7517d7f5a9d34a9ba5954a21a8317803/ alkoholstrategien-til-nett.pdf [accessed 2022-01-10]

22. Fysisk aktivitet for barn, unge, voksne, eldre og gravide. The Norwegian Directorate of Health. URL: https://www. helsedirektoratet.no/faglige-rad/fysisk-aktivitet-for-barn-unge-voksne-eldre-og-gravide [accessed 2022-02-10]

23. Norwegian dietary guidelines. The Norwegian Directorate of Health. URL: https://tinyurl.com/35embj77 [accessed 2022-02-10]

24. Muench F, Baumel A. More than a text message: dismantling digital triggers to curate behavior change in patient-centered health interventions. J Med Internet Res 2017 May 26;19(5):e147 [FREE Full text] [doi: 10.2196/jmir.7463] [Medline: 28550001]

25. Pariyo GW, Wosu AC, Gibson DG, Labrique AB, Ali J, Hyder AA. Moving the agenda on noncommunicable diseases: policy implications of mobile phone surveys in low and middle-income countries. J Med Internet Res 2017 May 05;19(5):e115 [FREE Full text] [doi: 10.2196/jmir.7302] [Medline: 28476720]

26. Ali J, Labrique AB, Gionfriddo K, Pariyo G, Gibson DG, Pratt B, et al. Ethics considerations in global mobile phone-based surveys of noncommunicable diseases: a conceptual exploration. J Med Internet Res 2017 May 05;19(5):e110 [FREE Full text] [doi: 10.2196/jmir.7326] [Medline: 28476723]

27. Gram IT, Larbi D, Wangberg SC. Comparing the efficacy of an identical, tailored smoking cessation intervention delivered by mobile text messaging versus email: randomized controlled trial. JMIR Mhealth Uhealth 2019 Sep 27;7(9):e12137 [FREE Full text] [doi: 10.2196/12137] [Medline: $\underline{\text { 31573935] }}$

28. Hansen AH, Bradway M, Broz J, Claudi T, Henriksen $\emptyset$, Wangberg SC, et al. Inequalities in the use of ehealth between socioeconomic groups among patients with type 1 and type 2 diabetes: cross-sectional study. J Med Internet Res 2019;21(5):e13615 [FREE Full text] [doi: 10.2196/13615] [Medline: 31144669]

29. Wangberg SC, Nilsen O, Antypas K, Gram IT. Effect of tailoring in an internet-based intervention for smoking cessation: randomized controlled trial. J Med Internet Res 2011 Dec 15;13(4):e121 [FREE Full text] [doi: 10.2196/jmir.1605] [Medline: 22169631]

30. Westmaas JL, Bontemps-Jones J, Hendricks PS, Kim J, Abroms LC. Randomised controlled trial of stand-alone tailored emails for smoking cessation. Tob Control 2018 Mar;27(2):136-146. [doi: 10.1136/tobaccocontrol-2016-053056] [Medline: 28522745]

31. Geldsetzer P. Use of rapid online surveys to assess people's perceptions during infectious disease outbreaks: a cross-sectional survey on COVID-19. J Med Internet Res 2020 Apr 02;22(4):e18790 [FREE Full text] [doi: 10.2196/18790] [Medline: $\underline{32240094]}$

32. Fry A, Littlejohns TJ, Sudlow C, Doherty N, Adamska L, Sprosen T, et al. Comparison of sociodemographic and health-related characteristics of UK biobank participants with those of the general population. Am J Epidemiol 2017 Nov 01;186(9):1026-1034 [FREE Full text] [doi: 10.1093/aje/kwx246] [Medline: 28641372]

33. Johnson TP, Wislar JS. Response rates and nonresponse errors in surveys. JAMA 2012 May 2;307(17):1805-1806. [doi: 10.1001/jama.2012.3532] [Medline: 22550194]

34. Eysenbach G. The law of attrition. J Med Internet Res 2005;7(1):e11 [FREE Full text] [doi: 10.2196/jmir.7.1.e11] [Medline: 15829473]

35. Edwards P, Roberts I, Clarke M, DiGuiseppi C, Pratap S, Wentz R, et al. Increasing response rates to postal questionnaires: systematic review. BMJ 2002 May 18;324(7347):1183 [FREE Full text] [Medline: 12016181]

36. Lund E, Gram IT. Response rate according to title and length of questionnaire. Scand J Soc Med 1998 Jun;26(2):154-160. [doi: 10.1177/14034948980260020401] [Medline: 9658516] 
37. Skogen JC, Knapstad M, Smith OR, Tell GS, Lie RT, Nilsen TS, et al. How should recruitment to public health surveys be conducted?

https://tidsskriftet.no/2019/10/originalartikkel/hvordan-bor-rekrutteringen-til-folkehelseundersokelsene-gjennomfores. URL: http://tidsskriftet.no/article/19-0054 [accessed 2020-02-10]

38. Abel M, Totland T. Kartlegging av kostholdsvanver og kroppsvekt hos voksne i Norge basert på selvrapportering- Resultater fra Den nasjonale folkehelseundersøkelsen. Norwegian Institute of Public Health. URL: $\underline{\text { https://www.fhi.no/globalassets/ }}$ dokumenterfiler/rapporter/2021/rapport-nhus-2020.pdf [accessed 2022-08-10]

39. Sund ER, van Lenthe FJ, Avendano M, Raina P, Krokstad S. Does urbanicity modify the relationship between a polygenic risk score for depression and mental health symptoms? cross-sectional evidence from the observational HUNT study in Norway. J Epidemiol Community Health 2021 May;75(5):420-425 [FREE Full text] [doi: 10.1136/jech-2020-214256] [Medline: 32581065]

40. Wettergreen J. Less Norwegians smoke, more use snus 2020. Statistics Norway. URL: https://www.ssb.no/en/helse/ artikler-og-publikasjoner/less-norwegians-smoke-more-use-snus [accessed 2021-10-30]

41. Arain M, Campbell MJ, Cooper CL, Lancaster GA. What is a pilot or feasibility study? a review of current practice and editorial policy. BMC Med Res Methodol 2010;10:67 [FREE Full text] [doi: 10.1186/1471-2288-10-67] [Medline: 20637084]

42. The Research Council of Norway. WARIFA: watching the risk factors: artificial intelligence and the personalized prevention and management of chronic conditions. Innovation Place. URL: https://www.innovationplace.eu/news/ warifa-project-artificial-intelligence-and-prevention-of-chronic-conditions [accessed 2021-10-29]

\section{Abbreviations \\ NOK: Norwegian Kroner}

Edited by G Eysenbach; submitted 08.11.21; peer-reviewed by J Westmaas; comments to author 29.11.21; revised version received
09.12.21; accepted 31.12.21; published 25.02 .22
Please cite as:
Gram IT, Skeie G, Oyeyemi SO, Borch KB, Hopstock LA, Løchen ML
A Smartphone-Based Information Communication Technology Solution for Primary Modifiable Risk Factors for Noncommunicable
Diseases: Pilot and Feasibility Study in Norway
JMIR Form Res 2022;6(2):e33636
URL: https://formative.jmir.org/2022/2/e33636
doi: $\underline{10.2196 / 33636}$
PMID:

CInger Torhild Gram, Guri Skeie, Sunday Oluwafemi Oyeyemi, Kristin Benjaminsen Borch, Laila Arnesdatter Hopstock, Maja-Lisa Løchen. Originally published in JMIR Formative Research (https://formative.jmir.org), 25.02.2022. This is an open-access article distributed under the terms of the Creative Commons Attribution License (https://creativecommons.org/licenses/by/4.0/), which permits unrestricted use, distribution, and reproduction in any medium, provided the original work, first published in JMIR Formative Research, is properly cited. The complete bibliographic information, a link to the original publication on https://formative.jmir.org, as well as this copyright and license information must be included. 